\title{
Technical vs. academic writing in English - Any difference for non-native writers?
}

Ines A. Busch-Lauer

\section{Q OpenEdition \\ 1 Journals}

\section{Electronic version}

URL: http://journals.openedition.org/asp/1454

DOI: 10.4000/asp.1454

ISBN: 978-2-8218-0390-9

ISSN: $2108-6354$

\section{Publisher}

Groupe d'étude et de recherche en anglais de spécialité

Printed version

Date of publication: 30 December 2002

Number of pages: $37-46$

ISSN: 1246-8185

\section{Electronic reference}

Ines A. Busch-Lauer, "Technical vs. academic writing in English - Any difference for non-native writers? », ASp [Online], 37-38 | 2002, Online since 21 July 2010, connection on 10 December 2020 URL : http://journals.openedition.org/asp/1454 ; DOI : https://doi.org/10.4000/asp.1454

This text was automatically generated on 10 December 2020.

Tous droits réservés 


\title{
Technical vs. academic writing in English - Any difference for non- native writers?
}

\author{
Ines A. Busch-Lauer
}

\section{Introduction}

1 Writing processes and written genres have been the subject of applied linguistic research for quite some time. However, there is still controversy of opinions regarding the factors which influence the writing process of non-native speakers of English (NNSE) in L2 and the factors which dominate their text products (cf. the research of Kaplan 1966; Galtung 1985; Clyne 1987, 1991; Gläser 1990; Gnutzmann/ Lange 1990, Connor 1996; Swales 1990; Ventola/ Mauranen 1991; Huckin 1997; Hutz 1997; Trumpp 1998).

2 This paper is devoted to a preliminary text analysis of NNSE text samples. Since the linguistic material is limited, the results of this study will only have a preliminary character and require further research. The paper focuses on the investigation of three major questions that result from the ESP-teaching experience of the author in academic and technical writing to a German native-speaker audience.

1. Is L2-writing predominantly determined by the language skills (both in L1 and L2) and the (inter)cultural experience of the writer, or is it rather a matter of genre awareness?

2. Do L2-texts of various genres and fields contain similar or different writing problems?

3. Are there any differences for non-native writers when writing technical and academic texts in English?

3 To provide an answer to these questions, we first examine some results of applied LSP and writing research. In the second part of the paper, randomly selected expert and student texts are considered which were taken from the fields of linguistics, medicine and computer science. Finally, the paper provides some conclusions for the teaching of writing in both classroom and corporate environments. In other words, the present paper 
tries to investigate the role of native and foreign languages, of genre and discipline constraints and of audience awareness in English texts produced by German authors.

\title{
1.1. Genres - A Brief Review of the Concept
}

4 The notion of genre as a basic concept to describe various classes of texts has been defined by Swales (1990) and Gläser (1990). In his comprehensive investigation on genres, Swales states that

\begin{abstract}
A genre comprises a class of communicative events, the members of which share some set of communicative purposes. These purposes are recognized by the expert members of the parent discourse community, and thereby constitute the rationale for the genre. This rationale shapes the schematic structure of the discourse and influences and constrains choice of content and style. Communicative purpose is both a privileged criterion and one that operates to keep the scope of a genre as here conceived narrowly focused on comparable rhetorical action. In addition to purpose, exemplars of a genre exhibit various patterns of similarity in terms of structure, style, content and intended audience. If all high probability expectations are realized, the exemplar will be viewed as prototypical by the parent discourse community. (1990: 58)
\end{abstract}

5 This definition already indicates that the genre has specific textual and extra-textual features that enable communication between the writer as a member of a certain discourse community and the reader. Therefore, adherence to the specific characteristics of a genre is important for the writer in order to make the intention of the text clear.

Gläser (1990) refers to genres as classes of texts that have developed historically and pursue a common communicative function recognised by the experts and members of a specific language community, e.g. scientists, technical writers or other expert and laypeople. This in fact means that writers have to consider the genre as a dominating factor with regard to textual communication which is due to the communicative intention of the author, the purpose of the text and its specific focus on a selected audience.

This dynamic character of genres is also considered by Huckin who states that genres are

[...] responsive to the rhetorical demands of particular situations. And inasmuch as particular situations invoke culture-specific features, genres themselves are culture-sensitive. This view explains, among other things, how 'genres change over time to their users'sociocognitive needs'. (1997: 77)

8 The analysis of texts and genres has resulted in various attempts to classify these types of texts. The most prominent German attempts in this respect were by Gläser (1990: 50), Göpferich (1995: 90) and Horn-Helf (1999: 153). Gläser classifies written genres into subject-internal and subject-external genres. Within the subject-internal genres, she subclassifies informative, interpersonal, directive and didactic texts. Didactic, popularising and directive texts are part of the subject-external communication. Using this subclassification, she then assigns prominent academic genres and describes selected criteria.

Göpferich (1995: 90) restricts her classification of genres to the natural sciences and technology. Her hierarchical model distinguishes 5 classification levels, each applying a different classification criterion. The classification criterion at the highest level is the communicative function; at the second level, it is the theory-practice relation; at the third level, she applies the type of information presentation and then she differentiates 
texts and genres according to their specific communicative intention into primary (e.g. report, scientific paper, instruction) and secondary genres (e.g., abstracts, summary, book review).

In contrast to these hierarchically structured approaches, Horn-Helf (1999: 153) lists the genres occurring most frequently in the translation practice. She combines this list with a thorough description of source and target text errors which provides writers and translators with an insight into the specific textual, linguistic and cultural criteria which they should focus on in their text production process. Among these texts are text types like instructions and reports but also technical genres such as technical manuals, patents, support agreements and the like.

11 Nonetheless, considering the current results provided by LSP research in the field of genre description and classification, one can think that they prove to be too theoretical for teaching purposes. The currently existing classifications and descriptions do not effectively help writers in their daily practice (neither in their mother tongue nor in English) because they do not provide generalised text components and stylistic advice.

For this reason LSP genre research has to focus on specific subjects in order to determine the most prominent genres used in them and to make these the subject of contrastive analyses (for example German-English). In this way the specific linguistic, text organisational and, if possible, culture-specific criteria can be figured out. These can be taught to novice writers and experts in order to improve their texts in L2. This process requires the co-operation of linguists and professionals of the field to avoid linguistic research being one-sided and representing the subjective view of the linguistic researcher only.

13 Text analyses and comparisons will eventually be the basis for the development of specific writing materials and result in a thorough classification of genres for a specific subject and in various disciplines.

\subsection{Writing Difficulties}

14 Everyone teaching writing has a vague idea of the kind of mistakes that may occur in texts written by NNSE. The study performed by Jordan (1997: 46) provides an overview of the writing difficulties encountered by students from their own judgement and from their tutor's point of view. Interestingly, the opinions between these groups differ. Among the highly rated difficulties seen from the point of view of the interviewed students were: vocabulary (62\%), style (53\%), spelling (41\%), grammar (38\%), punctuation (18\%) and handwriting (12\%). By contrast, the tutors of these students considered style as the most problematic factor (92\%), outweighing grammar $(77 \%)$, vocabulary (70 \%), handwriting (31 \%), punctuation ( $23 \%)$ and spelling ( $23 \%)$. Jenkins/ Jordan/ Weiland (1993) consider the evaluation criteria for native (NSE) and non-native speakers of English (NNSE) texts at several engineering faculties in the USA. Their research revealed that only $36 \%$ of the tutors used a different scale to evaluate NSE texts in English. The criteria for which they applied a 'milder' evaluation were: grammar/ sentence structure, appropriate vocabulary, punctuation and spelling and overall writing ability. Tutors rated the texts of NSE and NNSE almost in the same way with regard to contents, the structured and logical presentation of arguments and a clear statement of the problem and its solution. 
The research by Clyne (1987a, b) revealed that there are obviously more criteria that influence the quality of the text seen from the recipients' point of view. Among these factors are linearity, symmetry, continuity which seem to be typical of native English writing style.

In the second part of the paper, I will consider some of the problems German writers have when writing English texts and use a few sample texts for this purpose. I will then try to provide answers to the questions raised in the introduction of this paper. However, emphasis should be made on the fact that the linguistic sample on which this paper is based is very small. No definitive conclusion can therefore be drawn.

\section{Analysis of Academic and Technical Texts - Some Preliminary Results}

In the following part of this paper I will consider some texts written by German experts (linguists, medical researchers and students as well as technical writers) with regard to some of their textual flaws in order to illustrate writing problems. The first text which is considered is a medical abstract of a case report written by a team of German medical researchers. When writing an abstract, writers usually have to adhere to strict instructions to authors if they want to publish in an international journal. The sample text is taken from a German medical journal in which authors have to submit English abstracts for their articles. Abstracts are restricted in their length; therefore, the authors have to carefully select the information they want to provide to their readers. Since abstracts do not always accompany the scientific article, they should be self-explanatory and function as stand-alone texts.

Sample 1:

Summary: Besides the lungs, the liver is the second most common site of haematogenous metastases from carcinomata of the breast. Hepar lobatum carcinomatum is the rarest form of metastatic liver disease. Reported in this article is a case of a 59-year-old woman with invasive duct carcinoma of the breast with metastasis to the axillar lymph nodes and liver, treated with ablatio mammae and combination of chemotherapy. The etiology of hepar lobatum is caused by multiple pathogenetic factors. Tumor-related multifocal obstruction of portal and hepatic venous vessels and effects of chemotherapy are discussed.

Commentary:

The sample text fails the above-mentioned intention due to some deficiencies. First of all, one can notice that the author uses an unusual sequence of sentences (no topic sentence as in an English abstract, no explication of problem and solution). The sentence structure used results from direct negative transfer of German patterns into English (cf. italicised passages).

Moreover, the abstract suffers from a lack of coherence and cohesion. Each sentence seems to be unrelated to the others. The passive voice (commonly used in German scientific texts) is also transferred into the English text, thus resulting in an unusually long construction in the last sentence.

Sample 2: 
Summary: Understandability of texts and chemical contents is not selfcontradictory. This investigation shows that understandable texts with chemical contents are realizable, but they are not realized. It is a long way to go about it, especially concerning school-book-texts. With regard to the usual difficulties of students in reading and understanding chemical school-booktexts the rewritten text gives the opportunity of counteracting failures and supporting the learning process.

Commentary:

The second text under investigation was written by a German linguist who is experienced in writing scientific articles. However, as can be seen from the text, the abstract suffers from a number of insufficiencies including an unclear understanding of what purpose an abstract serves: unclear wording (e.g. understandability, realizable, school-book-text), redundancy (e.g., realizable, realized), stylistic insufficiency (it is a long way to go about it... give the opportunity), long sentence structure, no logical argumentation.

\section{Sample 3:}

During the last years the attention of many scientists has been drawn again to an inflammatory illness of the skin called atopic eczema. The illness known already in the classical antiquity has had many names in the course of time that are still being used, e.g. [...]. Today the term "atopic eczema" prevails in scientific publications because it describes the eczema occurring in atopics without suggesting a certain pathophysiological mechanism. However, there are some new starting points for the therapy of atopic eczema and although atopic eczema is still incurable at the moment the therapies might bring relief to the people suffering from it. According to a study of Prof. Wuthrich and U.W. Schnyder, Zurich, atopic eczema has increased worldwide during the last years. Today the risk for newborns to be affected by this illness of the skin is already $5-15 \%$ if both parents are healthy. In cases of both parents suffering from atopic eczema even $60-80 \%$ of the children will have the illness, too. This paper will give a short review on the illness affecting so many people in the world, especially the current pathophysiological concepts of atopic eczema as well as other factors that are being discussed to have an impact on the illness.

Commentary:

21 The third sample text was written by a German medical student as an introduction to a project which in fact resembles a scientific article (at least one can trace the moves described by Swales, e.g. stating the problem/ topic, establishing referenced to previous scientific work, announcing the specific topic of the article). Thus, the textual organisation seems to be fairly adequate, considering the experience a third-year student of medicine may have with this genre. However, one can clearly detect, inter alia, grammatical infelicities.

\section{Sample 4:}

Mankind needs a common language to survive. Is this true? Why we can't translate like we have the last thousand years ago? Today there are more international relations, more international business than in the last years. We speak about a united Europe, we travel all around the world. This causes translating official papers, scientific works, time tables, holiday descriptions into many languages. But translations cost time and money. Both we have not. For instance [...]. Because this arguments it would be nice if we had a common language. But which language should this be? An artificial or a natural? And if we decide for a natural, which of them? The problem with 
natural languages is that if we decide for one the speakers of some others will protest against this decision and ignore the common language. This has reasons in history or national proudness. And, by which facts should made this decision? By the number of speakers, then we have to take Chinese, by the economic influence, then we have to take English or German, by the easiest way to learn this language? The problem with artificial languages is, that at the beginning there are nearly no speakers and so nobody has a strong motivation to learn these languages. I think English would be a good decision, because today it is used at many different fields: in the sciences, in the air traffic, at business conferences, in the wireless communication in the army, for instance. We should not ignore this.

But I don't think that everybody must speak English or an other common language. Some people, who live only in their little village and never meet a foreigner, don't need this. At all I think we should not make to strong regulations, the "best" language will get common alone.

Commentary:

Text sample 4 is part of an essay written by a German student for an English language course and deals with the importance of learning foreign languages. The text has a clear structure: it first announces the topic and raises the questions which the author considers relevant to discuss in this context, i.e. the initial part of the essay addresses the problem. However, as one can already notice at the end of the first paragraph, the author has difficulties expressing his thoughts adequately and without making grammatical errors. Moreover, he uses a typical German method to focus his readers' attention to specific aspects: rhetorical questions. German sentence patterns can be traced in "And if we decide for a natural, which of them?" as well as in "And, by which facts should made his decision?". NNSEs obviously focus on the topic and neglect the language (in particular the grammar) or they do not revise the text once they have finished writing it. Moreover, one can also notice negative transfers from German into English in the use of punctuation and of connectors.

\section{Sample 5:}

This document describes the requirements for XXX. This system is the successor of XXX, primary consideration being given to the requirements of the YYY groups XXX Payment System". A problem in the electronic commerce and mobile commerce areas -for consumers as well as merchants and service providers -is secure payment processing, since their relationship is of a temporary nature and is restricted to the specific payment event. The consumer does not want to disclose the confidential information of his payment instrument to every merchant. On the other side, the merchant is interested in ensuring successful payment by the consumer in a way as simple as possible. The solution is to bring in a third party in the role of Payment Provider who has a contractual relationship with both the Consumer and the Merchant. In this constellation, payment processing requires that the consumer have equipment to pro-vide the necessary information about the payment instrument he is using. When the consumer is physically present with the merchant, this can be a point-of-sale data terminal for processing the consumer's credit card information. [...]

The use of a server makes sense not only for mobile channels (WAP, voice control by mobile phone/SMS) but also for the Internet, TV Commerce or Paper Bill. In contrast to the SET wallet, it does not assume the consumer has software or local data storage capabilities. The consumer needs only a Web browser or anything comparably. Consequently, this approach makes it possible to service various computers and simple terminals without long- 
term data storage. Moreover, dispensing with local data storage reduces security risks.

Commentary: industry. The text can be considered as an initial draft which has not yet undergone expert review. What can be noticed in this text is that the author had some difficulty organising its contents.The sentences are fairly long and hard to read.Connectors and cohesive elements are often missing. Moreover, due to several grammatical deficiencies, the text is sometimes difficult to understand. This causes the misunderstanding of sentences. Again we can also notice here that the author does not know how to use cohesive elements and is not aware of how much the English language system sometimes differs from the German.

\section{Results}

This brief analysis of the five text exemplars of this preliminary study shows that there are common writing problems across the genres and disciplines which, in turn, indicates that the quality of texts is strongly related to the language skills of the writer and to his/ her writing experience. However, since the linguistic sample of this study is small, the results of the analysis should only be considered indicative of some problems that deserve further research. Among the most common types of errors, which could be revealed in the samples, were the following:

- Wrong word selection and mistakes due to semantic/ phonetic similarity, terminological inconsistency, redundancy, false friends,

- Problems on the syntagmatic level (deletions, incompatibility of constituents, inconsistency in logical structure),

- Problems at the sentence level (inadequate wording, wrong negation, wrong association between sentence elements, grammatical mistakes such as the incompatibility of subject and predicate, wrong textual organization, too many long-winded sentences),

- Problems at the chunk level (logical inconsistency, for example in enumerations, logical structuring, wrong textual cohesion, unclear theme-rheme demarcation),

- Problems at the text level (intertextual and logical contradictions, fairly unorganised text patterns).

These insufficiencies can also be traced in the logical organisation of the textual contents, the text structure and lay-out. Mistakes and flaws are often related to the inadequate language proficiency of the writers and to a negative transfer of linguistic elements from the mother tongue to the foreign language - a process that seems to occur unconsciously. The authors of the five examples seem to have forgotten to review their texts and to be fairly unaware of the fact that every text addresses a specific audience. Most texts written by German writers are fairly writer-focused and not reader-focused as native English texts generally are.

The presented texts also seem to be fairly determined by subject and genre constraints. As a rule, medical texts follow a fairly strict sequence of chunk and moves. The essayistic text, in contrast, follows a fairly open pattern of argumentation - unlike English short essays. 
This investigation into medical, linguistic and technical text samples written by German authors (mostly post-intermediate - early advanced level writers in English) revealed that the language skills, experience and awareness of differences between the two language systems are decisive factors for the quality of the written text. Transfer of grammar patterns and sentences structures from L1 to L2 often results in mistakes and inadequacies that hamper the reading process. Moreover, it could be established that if system-related aspects differ significantly, the L2-texts suffer from substantial deficiencies.

Genre awareness combined with knowledge about text structures plays an important role for the target audience to better identify and understand the text. Therefore, genre analyses should focus on the microtextual level and not simply on the macrostructures. Another important observation is related to the fact that the more the writing relied on translation performed by laypeople, the worse the quality of the text because unprofessional authors often simply transfer the structures used in their mother tongue to the foreign language.

With regard to the questions raised at the beginning of this article we can state the following:

Is L2-writing predominantly determined by the language skills (both in L1 and L2) and the (inter)cultural experience of the writer, or is it rather a matter of genre awareness?

Texts of various genres and fields seem to present similar writing problems. These problems relate to the structure of the paragraphs, the cohesion used in the texts and the sentence focus.

This result indicates that there are culturally determined similarities and differences which originate from the different educational backgrounds of the writer and the expectation that there are no differences between one's own and the foreign language.

Do L2-texts of various genres and fields contain similar or different writing problems?

Texts of various genres and fields contain both similar and different writing problems which are, among other things, due to the unclear communicative purposes of the texts. For example, there are differences between descriptions (scientific articles) and instructions (technical manuals). However, the more the texts are standardised (cf. scientific abstracts), the more authors avoid any break of linguistic rules and follow the provided instructions. Nonetheless, inexperienced writers do not control their writing process because they often do not revise their texts beyond avoiding misprints. Moreover, technical and academic texts are different because of their different communicative purposes and textual organisation. Writing academic prose and technical documentation also differs because of different rules and language elements.

Are there any differences for non-native writers when writing technical and academic texts in English?

Writing L2-academic and technical texts is not so different for the L2-authors because in both cases they "struggle" with the foreign language system, the language skills and the different cultural expectations. They need to consider the different textual lay-out, the paragraph structure, cohesion, syntax and phrase level, lexeme level and spelling. This is why learners of a foreign language should be familiarised with the language system differences first, then with the textual and communicative differences which will finally result in increased genre awareness. They need to be trained in writing -from easy and 
short texts to complex and sophisticated communications. This, however, requires a lot of time and effort which is often not available.

In writing classes both in the classroom and in the corporate environment, it seems necessary first to determine the language level of the writer. Then the genres and text types which have to be taught should be defined according to the specific needs and the language level of the writer. For this purpose, it is also necessary to analyse corresponding texts of these genres in the mother tongue and the foreign language. The contents, audience and communicative intention need to be clear. Then, the writing process can start. We also need a shift from writer-oriented to reader-oriented writing because a number of NNSE cultures are often writer-focused. Moreover, familiarity with the process (from planning to revising) and with the required tools (dictionaries, grammar handbooks) is necessary and should be taught. What is also needed is a more process-oriented writing instruction with specific emphasis on text revision strategies. Towards that end, better contrastive analyses regarding text types and genres are required in order to increase the writers' genre awareness of the writers (cf. Björk/ Räisänen 1996; Barker 1998).

\section{BIBLIOGRAPHY}

Barker, Thomas T. 1998. Writing Software Documentation. A Task-Oriented Approach. New York: Prentice Hall.

Berkenkotter, C. \& Thomas Huckin. 1995. Genre knowledge in disciplinary communication. Cognition/ Culture/ Power. Hillsdale, NJ: Lawrence Erlbaum Ass.

Björk, Lennart \& Christine Räisänen. 1996. Academic Writing. A University Writing Course. Lund: Studentlitteratur.

Clyne, Michael. 1987a. "Discourse structures and discourse expectations: Implications for AngloGerman academic communication in English". In Smith, Larry E. (ed.), Discourse across cultures. Strategies in World Englishes. New York, London, Sydney, Tokyo: Elsevier Science Ltd, 73-83.

Clyne, Michael. 1987b. "Cultural differences in the organization of academic texts. English and German". Journal of Pragmatics 11, 211-247.

Clyne, Michael. 1991. "The sociocultural dimension -The dilemma of the German-speaking scholar". In Schröder, Hartmut (ed.), Subject-oriented Texts. Language of special purposes and text theory. Berlin, New York: Walter de Gruyter, 49-67.

Connor, Ulla. 1996. Contrastive rhetoric. Cross-cultural aspects of second-language writing. Cambridge: Cambridge University Press.

Galtung, Johan. 1985. "Struktur, Kultur und intellektueller Stil. Ein vergleichender Essay über sachsonische, teutonische, gallische und nipponische Wissenschaft". In Wierlacher, Alois (Hrsg.), Das Fremde und das Eigene. Prolegomena zu einer interkulturellen Germanistik. München: Iudicium, 151-193.

Gläser, Rosemarie. 1990. Fachtextsorten im Englischen. Tübingen: Gunter Narr Verlag. 
Gnutzmann, Claus \& Regina Lange. 1990. "Kontrastive Textlinguistik und Fachsprachenanalyse”. In Gnutzmann, Claus, Kontrastive Linguistik. [forum Angewandte Linguistik 19]. Frankfurt a.M: Lang, 85-116.

Göpferich, Susanne. 1995. Textsorten in Naturwissenschaften und Technik. Pragmatische Typologie Kontrastierung -Translation. Tübingen: Gunter Narr Verlag.

Horn-Helf, Brigitte. 1999. Technisches Übersetzen in Theorie und Praxis. Tübingen, Basel: Francke.

Huckin, Thomas. 1997. “Cultural aspects of genre knowledge”. AILA Review 12/6, Applied linguistics across disciplines, 68-78.

Hutz, Matthias. 1997. Kontrastive Fachtextlinguistik für den fachbezogenen Fremdsprachenunterricht. Fachzeitschriftenartikel der Psychologie im interlingualen Vergleich. Trier: WVT.

Jenkins, S., M. K. Jordan \& P.O. Weiland. 1993. "The role of writing in graduate engineering education: A survey of faculty beliefs and practices". ESP Journal 12/1, 51-68.

Jordan, Robert R. 1997. English for Academic Purposes. A Guide and Resource Book for Teachers. Cambridge: Cambridge University Press.

Kaplan, Robert B. 1966. "Cultural thought patterns in intercultural education”. Language Learning 16, 1-20.

Swales, John M. 1990. Genre analysis. English in academic and research settings. Cambridge: Cambridge University Press.

Trumpp, Eva Cassandra. 1998. Kultur-und textsortenspezifische Vertextungsstrategien. Eine kontrastive fachtextlinguistische Untersuchung zum Kommunikationsbereich der Sportwissenschaft: Englisch -Deutsch -Französisch. Tübingen: Gunter Narr Verlag.

Ventola, Eija \& Anna Mauranen. 1991. "Non-native writing and native revising of scientific articles". In Ventola, Eija (ed.), Functional and Systemic Linguistics. Approaches and Uses. Berlin: Mouton de Gruyter, 457-492.

\section{ABSTRACTS}

Writing processes and written genres have been the subject of applied linguistic research for quite some time. However, there is still controversy of opinions regarding the factors dominating the writing process of non-native speakers and their products. This paper focuses on whether L2writing is predominantly determined by the language skills (both in L1 and L2), the (inter)cultural experience of the writer, or whether it is rather a matter of communicative genre awareness. The results of the study of a small corpus in only three domains show that there are common problems that relate to the inadequate language proficiency of the writers and to a fairly unconscious transfer of linguistic elements of the mother tongue into the foreign language. Obviously there are similarities between the texts with respect to the kind of mistakes and the writing styles. On the other hand, the texts seem to be fairly determined by the subject and genre constraints. Further research is required to provide evidence for these preliminary assumptions.

Les processus d'écriture et les genres rédactionnels ont intéressé la recherche en linguistique appliquée depuis longtemps. Cependant, il y a toujours débat quant aux facteurs qui régissent les processus d'écriture des utilisateurs non-natifs et leurs productions. La présente étude essaie de déterminer si la rédaction en L2 est prioritairement déterminée par les compétences de langue (à la fois en L1 et en L2), l'expérience (inter)culturelle de l'auteur, ou si elle dépend plutôt d'une conscience de ce qu'est un genre communicationnel. Les résultats de l'étude d'un corpus limité, 
et dans trois domaines seulement, démontrent l'existence de problèmes communs liés à une compétence linguistique inadéquate des auteurs et à un transfert inconscient des éléments linguistiques de la langue maternelle vers la langue étrangère. Il existe évidemment des ressemblances entre les textes en ce qui concerne le type d'erreurs et les styles rédactionnels. D'autre part, les textes semblent être nettement déterminés par des contraintes tenant au genre et au sujet. Une recherche plus approfondie s'impose pour renforcer ces observations préliminaires.

\section{INDEX}

Keywords: academic text, genre, intercultural experience, L2-writing, native English speaker, non-native English speaker, technical text

Mots-clés: expérience interculturelle, genre, rédaction en $\mathrm{L} 2$, texte technique, texte universitaire, utilisateur natif, utilisateur non natif

\section{AUTHOR}

\section{INES A. BUSCH-LAUER}

